\title{
Design, Making and the Digitisation Trap
}

\section{Luca Barbieri}

Alma Mater Studiorum

— Università di Bologna

luca.barbieri17@unibo.it

ORCID 0000-0002-2728-1426
Andrea Cattabriga

Alma Mater Studiorum

— Università di Bologna

andrea.cattabriga@unibo.it

ORCID 0000-0003-0975-2025

\section{Abstract}

The article aims to investigate the evolutionary dynamics and critical issues emerging around makerspace communities, collaborative design and prototyping spaces whose practices have radically impacted the world of education, enterprise and social innovation.

Through an exploratory approach, experts from the maker movement and design students have been involved to understand the health of the model underlying makerspaces. The perspective of the research is to graft the debate on the forms of these practices into the dichotomy between physical and digital, socialization practices of design and the ability of these bottom-up models to work on complex solutions.

A list of recurring conditions occurring at the time of the creation of these communities has been elaborated. The discussion then covers risks and limitations of the physical dimension of makerspaces in relation with digitization of operations and relations at every level, calling for a necessary re-thinking of co-design practices.

\section{Keywords}

Industrial design

Maker movement

Makerspace

Prototyping

Design education 


\section{Introduction}

Prototyping and the associated methods of investigation have been always central to the design workflow in terms of the role prototyping plays in supporting concept generation, research and validation, and the relationship with the subjects and contexts in which takes place.

One of the most relevant phenomena of recent years, in the relationship between product development processes, prototyping technologies and the socialization of these phenomena, is undoubtedly the maker movement.

Much has been written about makers and the impact of their culture and workshop formats - makerspaces, fab labs, hackerspaces - on education, on business practice, and on local communities. These practices have made even the electronic and software components more accessible and prototypable to people with no specific background, enabling them to develop more complete and validated design solutions, bringing people and design closer to technologies.

The pandemic has accelerated numerous phenomena at every level of our global society, opening up profound questions concerning the fragility of supply chains, digitalization, and the need for interconnection between territories and communities. It has also affected makerspaces in an already delicate phase of their evolution, between post-hype settling, generational change and the digitalization of laboratory ecosystem.

In addition to prototyping practices, there are many themes that link the maker movement and design, including approaches such as distributed, participatory, collaborative, community and social design, open IP protection and distribution strategies, design for the do-it-yourself, and many others. These practices are all oriented towards interaction on the project among disparate stakeholders, collaboration and a radically open relationship with intellectual property, which is necessary to support a greater social impact of innovation. In the perspective of a hyper-connected reality, but one that is returning to talk about territories and communities, makerspaces are privileged places of great interest for the development of these design approaches.

This exploratory research seeks to interpret the transformations taking place in these prototyping and collaboration communities from a design-driven perspective, trying to identify the most critical elements and the most relevant development directions.

\section{Background}

We know how important the prototype is for the designer's process by supporting him/her in exploring, learning, refining and communicating the product (Camburn et al., 2017), but also for the whole system of actors that contribute to the descent to the market (Preece et al., 2015). There are many definitions of prototype (Jensen et al., 2016) and different taxonomies that help in understanding the relationship of the prototype according to different application contexts, function and goals of use (Petrakis et al., 
2019), but beyond its phenomenological dimension, it is possible to state with certainty that prototyping significantly increases the performance of the product (Camburn et al., 2017), of the creative process (Corsini \& Moultrie, 2017), making it an essential field of experimentation and work for designers.

Makerspaces are prototyping labs oriented towards learning digital and manual production technologies, culturally rooted in collaborative and open source practices, where making is intended as a learning tool and widely regarded as places of innovation (Kuznetsov \& Paulos, 2010). They are a family of accessible and often bottom-up prototyping spaces traceable to the "maker movement" (Anderson, 2012; Rosa et al., 2017), distributed and organized by global and local networks (Cattabriga, 2020). The makerspace format has been implemented in numerous fields (Dondlinger et al., 2017), including corporate (Rieken et al., 2020) and academic, the introduction of which has been considered as one of the most important developments in the education of designers and engineers (Khalifa \& Brahimi, 2017). Their presence seem to be able to produce a positive impact in local communities (Taylor et al., 2016), also through the ability to match the physical and digital world (Lindtner, 2014). Makerspace activates inclusive processes around technologies and highlighting the sense of prototyping also as a tool for developing shared knowledge (Kleinsmann \& Bhömer, 2020).

During the COVID-19 pandemic, makers represented a bottom-up emergency response system based on distributed production (Corsini, Dammicco, Bowker-Lonnecker et al., 2020; Harris et al., 2020; Armstrong et al., 2020) and brought back to center stage a crucial debate on intellectual property in crisis contexts (Mahr \& Dickel, 2020). However, the crisis has stressed elements of fragility such as the credibility of makers in production chains and the effective orchestration capacity of projects contributors (Corsini, Dammicco \& Moultrie, 2020), adding elements to a list of structural criticalities of the movement (Smith, 2017).

We are living in a complex global context that the pandemic has projected even more rapidly towards the need for interconnected local and community solutions (Manzini \& Menichinelli, 2021), in which the makerspace model can constitute an important infrastructure for territories, determining a challenge of maturity for the maker movement, but also for design, which is increasingly called upon to confront technologies, dialoguing with communities in a paradigm of open, distributed and collaborative fashion.

\section{Methodology and Results}

This exploratory research is based on a series of semi-structured interviews with 11 experts from the world of makers and with experience of running these spaces. Then a questionnaire addressed to 147 students has been developed in order to validate in the present some themes that emerged in the interviews and referring to recurring contextual conditions emerged at the time of the creation of makerspaces. This is relevant due to the fact that makerspace founders are very often graduates or students of design disciplines. 
The qualitative part of the research was conducted following the framework proposed (Pope et al., 2000).

The selected experts, mostly Italian, also represent a taxonomy of organization and purpose of the various forms that makerspaces have adopted between profit and non-profit.

The individual semi-structured interviews (carried out in March 2021), were conducted by video-call following a pattern of questions based on three macro themes useful for observing these communities in an evolutionary dynamic:

- "Makers and communities before the lab" or the conditions

that led to the creation of a makerspace or fab lab;

- $\quad$ "Community after the lab" dealing with the conditions that

lead to the creation of autonomous initiatives outside the lab;

- "The community during COVID".

Insights were then obtained from the analysis of the transcripts, focusing on common and divergent themes. In the last phase, the emerging themes were sifted through by the entire team collaboratively on an online digital board, and then aggregated into semantic clusters, which were then used for the present discussion supported by references in the literature.

The questionnaire was addressed to students of Design degree courses at the Alma Mater Studiorum - Università di Bologna selected from the third year of the three-year degree to the second year of the master degree, so that they had already had prototyping experience (147 responses obtained).

In summary, the results that emerged from the interviews show a general framework that, starting from the synthesis of concepts shared by the interviewees, allowed us to develop a vision as contemporary as possible of the debate underway in the movement.

It was also possible to isolate a subset of factors that emerged as conditions that recur when makerspaces are created Tab. I.

In order to compare and verify some of the concepts that emerged in the interviews, a survey has been carried out among students of Design degree courses at the Alma Mater Studiorum Università di Bologna.

\section{Conditions.}

- The need to share a practice with others before a material need.

- Equipment sharing as the first purpose on which the community is based.

- There is a great thematic diversity in the project areas, which are becoming more specialized over time, with a strong link to local expertise.

- The physical space of the laboratory is the main activator of spontaneous collaborations between members.

- Founders often have a background of studies in project disciplines.

- The founders are often members of vertical communities on individual technologies, processing techniques or specific software that find a home in the lab.

- Design and prototyping in the field are a privileged vehicle for the transfer of skills. 


\section{Discussion}

From our interviews emerges how the "makers model" (types of spaces, processes and culture), despite the crisis of the phenomenon, seems to have integrated well with both the world of school and business. This, thanks to the professionalization of a class of lab managers increasingly able to coordinate partners of different natures and a great thematic variability of projects. This aspect, combined with the creation of a denser system of professional relationships within this circle of makers - both with own collaborators and between managers of different workshops - opens the way to a greater capacity to produce impact. A social capital which the pandemic seems to have consolidated, while it seems to have compromised, perhaps irremediably, the relationships of the less engaged parts of the communities.

The lively interaction between makers and businesses, although uneven across labs, despite known problems of mutual alignment (Tabarés \& Kuittinen, 2020) and evolving out of known patterns (Schøsler \& Farbøl, 2015), seems limited to a minority of more market and research-oriented makerspaces, differentiated from those based on volunteering and remaining more bound to early models.

In the proliferation of the latest consolidated branches of design (from that of experience to that of transition), we can already see a certain overlap with the terrains on which makers imagine they will have to develop solutions in the coming years.

However, the eternal question of the "makers' way" of developing projects remains central, which despite progresses reported, very often struggles to find space in the market.

This always makes the sustainability of makerspaces of private initiative too fragile, reconfiguring a necessary compromise between the time required for the process of cultural acceptance of makers' practices (necessarily long for the consolidation of good relations with external partners), design and operational iterative approach (necessary to produce impact and quality results), with the ability to work on ever-increasing levels of complexity.

\section{Physical Product and Location Limits in the Interaction With the Digital World}

Despite the widespread ethical rigor and affection of the maker world for the development of physical product projects with the open-source approach (open hardware), it seems to cost in terms of scalability and team cohesion. In this regard, Hausberg and Spaeth (2020) report a clear overlap between the motivational levers of members in software open-source communities and those in open hardware ones, pointing the way of the adoption by the latter of collaborative practices closer to those of the former. However, it should be borne in mind that sharing a hardware project poses specific challenges. Some are well known, such as the fact that open hardware projects have a physiologically much more limited participation than software ones; for Bonvoisin et al. (2018) the solution would be to move from a model defined as hobbyist to a more 
industrial one. Other new ones that could therefore overturn some commonplaces of the maker community emerge from this research:

- the relationship with the reproducibility of a protectable and economically valuable invention, which inhibits its sharing; the scarce digitalization of the documentation of makerspace projects and processes (necessary for the opensource process);

- the greater influence of intrinsic motivational levers compared to ideological and ethical ones, referring to sharing (Hausberg \& Spaeth, 2020).

At the same time, frequenting a physical space poses a dilemma: while it is certainly necessary to access makerspace equipment (which is an activator an activator of peer learning, the heart of makerspace services and a facilitator of collaborations between members), it could be a possible obstacle for the new generations and in general for a society whose relationships are increasingly digitalized. This trend is also consistent with the growing share of digital projects developed by makerspaces. The acceleration induced by the pandemic on the digital remotization of processes - including those of makerspaces - has so far brought benefits in terms of internal operations (as reported by the majority of those interviewed), but has probably created more friction on the front of involvement, coordination of working groups and limited the opportunities for skills development (on which these places were based), posing new challenges in pedagogical, sociological and design terms. As suggested by the reflection of Lember et al. (2019), in addition to a widespread tendency towards techno-optimism focusing on positive case studies, more rigor is needed in analyzing the combined effect of digital technologies in the dynamics of co-production and co-creation as they might also have negative effects in terms of people's engagement and motivation.

\section{Makers and Design Education}

The results of the questionnaire, implemented to support the interviews, confirm the problematic relationship between students and prototyping (Carfagni et al., 2020), which still struggles to be resolved despite many studies and successful experimentations. For example, Hilton et al. (2018) demonstrated that attending makerspaces positively impacts on students' performances. But to solve it, it seems useful to correctly frame the approach to these practices by integrating them into teaching with attention to methodologies and prototype requirements, in relation to the design phase purpose and students' motivations (Carfagni et al., 2020). Given the strong continuity that exists between students of design disciplines and the maker community, we believe it is now relevant in this historical moment to insist on greater integration between the training of designers and processes related to making, investigating new formats and experiences that can combine two aspects:

1 a prototyping experience more calibrated on the specific training curriculum (motivational levers, ways of acquiring skills and correct declination of the prototype in terms of definition, purpose and technical requirements); 
increasing the students' ability to relate to each other in the physical and social context of makerspaces, otherwise reconfigure the makerspace itself to better meet new generations' propensity for more controllable interactions and to levels of complexity on which they can feel confident to interact profitably.

\section{Conclusions}

The research, carried out by interpolating the experience of experts from the maker world and a community of design students, investigated makerspace communities as community prototyping places, thus acting as a bridge between design practices and territories.

A set of recurring contextual conditions occurring at the establishment of makerspaces has been identified, as well as a number of topics to be explored in further research, concerning relations with the business world, the challenges facing these places based on the attendance of the physical space, and issues related to open hardware communities. In addition to these criticalities, according to the authors, there is a need to investigate the extent to which the digitization of processes constitutes a main pitfall for makerspace communities, making it necessary to carry out an in-depth investigation into how to mediate and compensate for its effects.

These insights emerge at a time of combination between an apparent crisis for the maker movement on the one hand (exacerbated, but not caused, by the pandemic) and a growing cultural orientation in favor of community-centered development strategies on the other. This forces us to reflect in an up-to-date, less ideological and more technical way on how design can interact with these practices on both the cultural and strategic dimensions, as well as at the level of prototyping dynamics and process design.

\section{Acknowledgements}

The authors would like to thank Professor Michele Zannoni of the Università di Bologna for the essential discussion from which this research started.

\section{References}

Anderson, C. (2012). Makers: The New Industrial Revolution. Crown.

Armstrong, K., Toribio Sánchez, P., \& Whyman, E. (Eds.). (2020). Viral Design. The Covid-19 Crisis as a Global Test Bed for Distributed Design. Institute for Advanced Architecture of Catalonia. https://distributeddesign.eu/viral-design-book/

\section{Luca Barbieri}

Luca Barbieri is a Research Fellow in the Department of Architecture at the University of Bologna. Graduated in Interaction design at the Università degli Studi della Repubblica di San Marino, then research fellow on physical and digital prototyping with a particular focus on enabling technologies.

\section{Andrea Cattabriga}

Andrea Cattabriga is a strategic designer and expert of collaborative innovation practices. He is a Ph.D. fellow in the Department of Architecture at the Alma Mater Studiorum - Università di Bologna, where he has collaborated as research fellow, contract professor and teaching tutor since 2019. He has co-founded Slow/d (2011), an award-winning design firm, Junto Innovation Hub in Modena (2020), and he is president of Mak-ER (regional network of fab labs and makerspace in Emilia-Romagna). His current research investigates how to benefit participatory design and citizen science practices with artificial intelligence.
Carfagni, M., Fiorineschi, L., Furferi, R., Governi, L., \& Rotini, F. (2020). Usefulness of prototypes in conceptual design: students' view. International Journal on Interactive Design and Manufacturing (IJIDeM), 14(4), 1305-1319. https://doi.org/ gjjzfh 
Cattabriga, A., Barbieri, L., \& Zannoni, M. (2021). Design, making and the digitisation trap: expert interviews and questionnaire (Version 1.0) [Data set]. Zenodo. http:// doi.org/10.5281/zenodo.4738833

Cattabriga, A. (2020). A Makerspace Network as Part of a Regional Innovation Ecosystem, the Case of Emilia-Romagna. European Journal of Creative Practices in Cities and Landscapes, Vol 2, 83-103. https://doi.org/10.6092/ ISSN.2612-0496/9536

Corsini, L., Dammicco, V., Bowker-Lonnecker, L., \& Blythe, R. (2020). The Maker movement and its impact in the fight against COVID-19 [Working Paper]. https:// www.repository.cam.ac.uk/ handle/1810/313163

Corsini, L., Dammicco, V., \& Moultrie, J. (2020). Critical Factors for Implementing Open Source Hardware in a Crisis: Lessons Learned from the COVID-19

Pandemic. Journal of Open Hardware, 4(1), 8. https:// doi.org/10.5334/joh.24

Corsini, L., \& Moultrie, J. (2017). An exploratory study into the impact of new digital design and manufacturing tools on the design process. DS 87-2 Proceedings of the $21 \mathrm{st}$ International Conference on Engineering Design (ICED

17) Vol 2: Design Processes, Design Organisation and Management, Vancouver, Canada, 21-25.08.2017. https://www.designsociety. org/publication/39556/ An+exploratory+study +into+the+impact+of+new+ digital+design+and +manufacturing+tools+on+ the+design+process

Dondlinger, M. J., McLeod, J., \& Bigenho, C. (2017). Special Issue on Makerspace Design Cases. International Journal of Designs for Learning, 8(1). https://doi.org/10.14434/ ijdl.v8i1.23672
Harris, M., Bhatti, Y., Buckley, J., \& Sharma, D. (2020). Fast and frugal innovations in response to the COVID-19 pandemic. Nature Medicine, 26(6), 814-817. https://doi.org/10.1038/ s41591-020-0889-1

Hausberg, J. P., \& Spaeth, S. (2020). Why makers make what they make: motivations to contribute to open source hardware development. R\&D Management, 50(1), 75-95. https://doi.org/ https://doi.org/10.1111/ radm.12348

Hilton, E.C., Nagel, R.L., \& Linsey, J.S. (2018). Makerspace Involvement and Academic Success in Mechanical Engineering. 2018 IEEE Frontiers in Education Conference (FIE), 1-5. https://doi.org/10.1109/ FIE.2018.8658875

Jensen, L.S., Özkil, A. G., \& Mortensen, N. H. (2016). Prototypes in engineering design: Definitions and strategies. $D S$ 84: Proceedings of the DESIGN 2016 14th International Design Conference, 821-830. https:// www.designsociety.org/ publication/38892/PROTOTYPES+IN+ENGINEERING+DESIGN\%3A+DEFINITIONS+AND+STRATEGIES

Khalifa, S., \& Brahimi, T. (2017). Makerspace: A novel approach to creative learning. 2017 Learning and Technology Conference ( $L$ T) - The MakerSpace: From Imagining to Making!, 4348. https://doi.org/10.1109/ LT.2017.8088125

Kleinsmann, M., \& Bhömer, M. (2020). The (New) Roles of Prototypes During the Co-Development of Digital Product Service Systems. International Journal of Design, 14(1), 65-79. http:// www.proquest.com/ docview/2404171002/ abstract/95D436F68ADC4437PQ/1
Kuznetsov, S., \& Paulos, E. (2010). Rise of the expert amateur: DIY projects, communities, and cultures. Proceedings of the 6th Nordic Conference on Human-Computer Interaction: Extending Boundaries, 295-304. https://doi. org/10.1145/1868914. 1868950

Lember, V., Brandsen, T., \& Tõnurist, P. (2019). The potential impacts of digital technologies on co-production and co-creation. Public Management Review, 21(11), 1665-1686. https:// doi.org/10.1080/14719037 2019.1619807

Lindtner, S. (2014). Hackerspaces and the Internet of Things in China: How makers are reinventing industrial production, innovation, and the self. China Information, 28(2), 145-167. https://doi.org/b56h

Mahr, D., \& Dickel, S. (2020). Rethinking intellectual property rights and commons-based peer production in times of crisis: The case of COVID-19 and 3D printed medical devices. Journal of Intellectual Property Law \& Practice, 15(9), 711-717. https://doi. org/10.1093/jiplp/jpaa124

Manzini, E., \& Menichinelli, M. (2021). Platforms for re-localization. Communities and places in the post-pandemic hybrid spaces. Strategic Design Research Journal, 14(1), 351-360. https:// doi.org/10.4013/

sdrj.2021.14.21432

Petrakis, K., Hird, A., \& Wodehouse, A. (2019). The Concept of Purposeful Prototyping: Towards a New Kind of Taxonomic Classification. Proceedings of the Design Society: International Conference on Engineering Design, 1(1), 1643-1652. https://doi. org/10.1017/dsi.2019.170

Pope, C., Ziebland, S., \& Mays, N. (2000). Analysing qualitative data. $B M J$, 320(7227), 114-116. https:// doi.org/bmj3cp
Preece, J., Sharp, H., \& Rogers, Y. (2015). Interaction Design: Beyond Human-Computer Interaction. John Wiley \& Sons.

Rieken, F., Boehm, T., Heinzen, M., \& Meboldt, M. (2020). Corporate makerspaces as innovation driver in companies: a literature review-based framework. Journal of Manufacturing Technology Management, 31(1), 91-123. Scopus. https://doi.org/10.1108/ JMTM-03-2019-0098

Rosa, P., Ferretti, F., Guimarães Pereira, Â., Panella, F., \& Wanner, M. (2017). Overview of the Maker Movement in the European Union. Publications Office of the European Union. https://ec.europa.eu/jrc/en/ publication/overview-maker-movement-european-union

Schøsler, M., \& Farbøl, H. I. (2015). Accessing a World of Distributed Innovation: Firm-Makerspace Collaboration. 154.

Smith, A. (2017). Social Innovation, Democracy and Makerspaces. Ssrn, 10. https://doi.org/10.2139/ ssrn.2986245

Tabarés, R., \& Kuittinen, $\mathrm{H}$. (2020). A tale of two innovation cultures: Bridging the gap between makers and manufacturers. Technology in Society, 63, 101352. https://doi.org/gh4m79

Taylor, N., Hurley, U., \& Connolly, P. (2016). Making Community: The Wider Role of Makerspaces in Public Life. Proceedings of the 2016 CHI Conference on Human Factors in Comput ing Systems, 1415-1425. https://doi.org/10.1145/ 2858036.2858073 